\title{
Assessment of Physico-Chemical and Ecological Variables in Selected Natural Breeding Sites of Mosquitoes in Ibadan, Oyo State, Nigeria
}

\author{
Owolabi DO and Bagbe AS* \\ Department of Biological Sciences, Ondo State University of Science and Technology, Nigeria
}

*Corresponding author: Bagbe AS, Department of Biological Sciences, Ondo State University of Science and Technology, Okitipupa, Ondo State, Nigeria.
Received Date: June 03, 2019

Published Date: June 28, 2019

\begin{abstract}
Larval habitats have been described as important determinants of adult distribution and abundance. Mosquitoes employ aquatic environment for growth and development, thus, a study of the factors that determine their habitat selection and preference is important for their occurrence. It also makes it possible to predict the type of disease, offer a precise prevention and suggest a likely control measure in combating mosquitoes in an area. The data required was obtained through field and laboratory works. The physico-chemical parameters considered were; temperature, pH, conductivity. Dissolved Oxygen, Biochemical Oxygen Demand and Chemical Oxygen Demand, and the ecological sites were; road puddle, sunlit pool, gutter, swamp and small drains. The temperature, $\mathrm{pH}$ and conductivity were recorded in situ while water sample from the sites were fixed and taken to the laboratory. Eleven Local Government Areas were visited, two locations each were picked at random from the areas and three sites were selected in each locations from the possible sites examined. A total number of 66 breeding sites examined consisted of 27 Culex sp., 25 Anopheles sp and 14 for both. Gutter had the highest percentage (55.56\%) occurrence of Culex sp., while it was least encountered in sunlit pool. Road puddle had the highest (56\%) for Anopheles sp. but was least in small drain and swamp. The temperature of the breeding sites ranged from 25 to $35^{\circ} \mathrm{C}$ with a mean value of $30^{\circ} \mathrm{C}$, the $\mathrm{pH}$ ranged from 2.5 to 9.5 with a mean value of 6.0, the conductivity ranged from 010 to 1620 with a mean of 815 , the Dissolved Oxygen ranged from 1.02 to 11.18, the Biochemical Oxygen Demand ranged from 5.40 to 22.96 and the Chemical Oxygen Demand ranged from 76.45 to 320.15 . The implication of these observations was discussed in relation to the success of the species in the habitats.
\end{abstract}

Keywords: Anopheles; Culex; Breeding sites; Preference; Ecological variables; Sunlit pool; Occurrence

\section{Introduction}

Mosquito belongs to the family Culicidae, order Diptera. Over 3,000 known species had been identified. The family Culicidae is a large, abundant, well-known and important group of flies. The early stages; egg, larval and pupal are aquatic. Mosquito larvae or wigglers are found in variety of aquatic situations such as ponds, pools, water in artificial containers, in tree holes with each species occurring in particular type of aquatic habitat [1,2]. The larvae of most species feed on algae and organic debris but a few are predaceous and feed on other mosquito larvae.When considering human welfare, mosquitoes are important because the females of many species are blood suckers, they annoy humans and other animals, and they may transmit the pathogens that cause human and animal diseases. The pathogens transmitted by mosquitoes include viruses (arboviruses), filarial worms (helminths) and protozoa. Mosquitoes are the indirect cause of more morbidity and mortality among humans than any other group of organisms [3].

An estimated 1.1 million people are infected by these diseases each year. Among these, Malaria, transmitted by Anopheles species is the worst and according to WHO [4], it infects nearly half a billion people, resulting in several million deaths worldwide each year. The Anopheles mosquito usually lays its egg singly on the surface of the water while Culex lays its egg in rafts on water surface. Anopheles larvae are found chiefly in ground pools, marshes and in places where there is considerable vegetation while Culex mosquitoes breed in varying places including artificial containers [5].

All mosquito larvae need standing water to complete their development. They utilize the relatively undisturbed surface tension of still waters and are not found in moving streams. They usually rise 
to the surface of the water and hang attached to the surface tension layer (at an angle characteristic of their species) to breathe, with their siphon tubes piercing through to the atmosphere. Anopheles lacks the siphon but breathe by lying parallel to the water surface with bristles causing them to float with their spiracles (breathing openings) above the surface.

Controlling mosquitoes and the diseases they transmit had been a major concern globally. The different strategies formulated at different times have been insufficient in many parts of the world to eradicate mosquitoes. Larval habitats have been described as important determinants of adult distribution and abundance and the understanding of the dynamics and productivity of larval habitats is required if the efforts to model and predict adult abundance are to succeed [3]. Therefore, it is expected that this will enable the prediction of the type of disease in a particular area and thus offer a precise suggestion on prevention and possible control measure to employ in combating mosquitoes.

The main objective of this project was to determine the occurrence and survival of the immature stages of Anopheles and Culex mosquitoes in Ibadan, Oyo State. The study investigated the physicochemical parameters that determine the breeding sites of the two species. It involves a comparison of these factors in the occurrence of these mosquitoes singly or jointly in a given habitat. It also assessed the suitability of the various sites examined as mosquito habitats. The influence of different habitats on the degree of the physiochemical parameters forms an important tool in assessing the occurrence and survival of a particular species in a place.

Generally, mosquitoes are reported to occupy a range of habitats and can withstand extreme environmental conditions. In the work of Gigmig et al [6], it was reported that different species of Anopheles showed preference to different habitats which ranged from temporary sunlit pools (where Anopheles gambiae are found) to permanent habitats such as rice fields, garden wells etc (where An arabiensis are found). On the other hand, Culex mosquito were said to inhabit all continents except Anartica. It was found in urban settings and every area inhabited by humans. It was also reported by Anderson and Harrington [7] that Culex mosquito prefers to lay eggs in polluted or stagnant waters, such that their presence in a water body is an indication of pollution but Anopheles breed in clear water of a suitable $\mathrm{pH}$, temperature, and nutrient composition.

The report given by Nikookar, et al, [8] pointed out that an apparent relationship exists between mosquito breeding and poor water quality. High levels of dissolved organic matter are said to provide nutrients for the bacteria and algae used as food by mosquito larvae. Larval density was also said to depend on factors like type of plant cover, food availability and predator abundance. Aquatic vegetation promotes anopheline production in addition to the provision of refuge to larvae against predation, it also enhances food resource as well as shelter from physical disturbance and provide favorable conditions for oviposition $[9,10]$.

\section{Materials and Methods}

\section{Study area}

Ibadan is the pinnacle of pre-colonial urban development in Nigeria with total land area of $3123 \mathrm{~km} 2$. It is located near the forest grassland boundary of South Western Nigeria lying between longitude 2 " $50^{\prime}$ and $3^{\circ} 20^{\prime}$ east of Greenwich meridian and latitude $7^{\circ} 20^{\prime}$ and $7^{\prime \prime} 50^{\prime}$ north of the equator. The mean annual rainfall was $125.9 \mathrm{~mm}$ from 1911-1988. The least value was recorded in 1983 as $786.4 \mathrm{~mm}$ while (lie highest values of $1981.2 \mathrm{~mm}$ and $1938 \mathrm{~mm}$ were recorded in 1968 and 1980 [11].

Ibadan city consists of urban and suburban districts. It was defined as the area extending about $55 \mathrm{~km}$ from Asejire in the east to Agemo in the West and for about $70 \mathrm{~km}$ from Iroko in the North to Manu in the South. The area is now made up of the following Local Governments; Akinyele, Egbeda, Ido, Ibadan North West, Lagelu. Oluyole, Ona-ara, Ibadan North East, Ibadan South East, Ibadan South West and Ibadan North [12].

Mosquito larvae were taken from various open waters regarded as the breeding sites of the mosquito all over the eleven local government areas in the study area as shown in Table 1. Two different zones were visited in each local government and three different breeding sites were sampled in each of the zones for the presence of Culex, Anopheles and both.

Table 1: Local Government Areas and the Areas sampled.

\begin{tabular}{|c|c|c|}
\hline L.G.A & Zone 1 & Zone 2 \\
\hline Ona Ara & Akanran & Olunloyo \\
\hline South west & Oke Ado & Odo Ona \\
\hline Northwest & Eleyele & Dugbe \\
\hline Oluyole & Adebayo & Idi Ayunre \\
\hline Southeast & Felele & Odinjo \\
\hline Ido & Ido & Omi Adio \\
\hline Egbeda & Egbeda & Erunmu \\
\hline Ibadan North & Mokola & Bodija \\
\hline Akinyele & Ojoo & Moniya \\
\hline Lagelu & lyana Offa & Adedodun \\
\hline Northeast & Beere & Oke-badan \\
\hline
\end{tabular}

The open waters sampled were categorized as road puddles, swamps, sunlit pool, small drain and gutter. The road puddles include the various potholes, tyre tracks etc found on the road. The swamps are waterlogged areas that are large and more or less permanent. The sunlit pools represent the transient pools found in open fields. While the small pools found around houses are considered as small drain and the gutters are the various manmade holes that hold water.

\section{Field assessment and laboratory analysis}

The data required for this project was obtained through field and laboratory works. From the various aquatic sites observed as the breeding sites of Culex or Anopheles or both, the physicochemical parameters which include temperature, conductivity, $\mathrm{pH}$, dissolved oxygen, etc were determined. Some of the parameters like 
temperature, $\mathrm{pH}$ and conductivity were determined in situ using field probe, while others were determined in the laboratory from the water samples taken from the various sampled sites.

\section{Physicochemical parameters}

The physicochemical parameters determined were water temperature, $\mathrm{pH}$, conductivity, dissolved oxygen (DO), Biological Oxygen Demand (BOD) and the chemical oxygen demand (COD).

\section{Statistical analysis}

The mean values, standard deviation and variance of all the parameters taken for each group stated above were determined. The physicochemical parameters of the water samples containing Anopheles and Culex mosquito were compared to determine the significant relationship among them.Linear regression analysis was used to test the significance of the effect of the physico-chemical parameters while single analysis of variance was used to test the statistical significance of the physico-chemical parameters across the breeding sites. Duncan Multiple Range Test was also used to compare the means of the physico-chemical parameter with significant mean differences across the breeding sites.

\section{Result}

Out of the 66 breeding sites examined, Culex sp was found in 27 sites accounting for $40.91 \%$ of the total number of sites sampled. While Anopheles sp. was recorded in 25 sites (37.88\%) with both co-habiting in 14 breeding sites of $21.21 \%$ of the total sites sampled

\section{Physicochemical parameters}

Table 3: Physicochemical parameters of the breeding sites.

\begin{tabular}{|c|c|c|c|c|c|c|}
\hline \multicolumn{7}{|c|}{ Habitats } \\
\hline \multicolumn{2}{|c|}{ Parameters } & Small drain & Gutter & Road puddle & Sunlit pool & Swamp \\
\hline \multirow{4}{*}{ Temp. } & An & $32.00+-0.00$ & $30.50+-1.50$ & $28.93-0.55$ & $30.40-0.50$ & $27.00-+0.00$ \\
\hline & $\mathrm{Cx}$ & $29.00+\_0.00$ & $29.25+2.06$ & $29.73+\_0.62$ & $30.20+0.86$ & $32.00+-1.00$ \\
\hline & An \& Cx & $32.00+0.00$ & $29.5+\_1.04$ & $31.75+0.75$ & $28.75+0.75$ & $28.00+\_0.00$ \\
\hline & An & $5.20+-0.00$ & $7.90+-0.11$ & $8.09+-0.12$ & $7.78+-0.36$ & $7.30+-0.00$ \\
\hline \multirow{3}{*}{$\mathrm{PH}$} & $\mathrm{Cx}$ & $8.20+\_0.00$ & $7.25+\_1.56$ & $7.80+\_0.42$ & $5.86+\_1.25$ & $8.75+\_0.75$ \\
\hline & $A n \& C x$ & $8.4+\_0.00$ & $8.10+\_0.20$ & $8.13+\_0.15$ & $8.23+\_0.21$ & $8.90+\_0.00$ \\
\hline & An & $55.00+-0.00$ & $607.50+-180.75$ & $322.86+-52.69$ & $588.00+-86.45$ & $60.00+-0.00$ \\
\hline \multirow{3}{*}{ Conductivity } & $\mathrm{Cx}$ & $1000+\_0.00$ & $125.0+60.89$ & $600.33+\_108.67$ & 398.00+_208.33 & $460.00+70.00$ \\
\hline & An \& Cx & $11.3+-0.00$ & $420.65+-277.95$ & $410.00+1117.26$ & 477.50+_117.41 & $310.00+0.00$ \\
\hline & An & $8.13+-0.00$ & $5.00+-1.18$ & $7.31+-0.66$ & $5.48+-0.71$ & $11.79+-0.93$ \\
\hline \multirow{3}{*}{ DO } & $C x$ & $2.03+\_0.00$ & $6.73+\_1.33$ & $5.52+\_0.84$ & $6.09+\_1.16$ & $10.29+\_0.08$ \\
\hline & An \& Cx & $1.16+-0.00$ & $4.44+\_0.96$ & $6.86+-0.77$ & $5.43+-1.19$ & $8.94+-0.00$ \\
\hline & An & $9.78+-0.00$ & $11.62+-1.02$ & $10.41+-0.56$ & $11.79+-0.93$ & $12.16+-0.00$ \\
\hline \multirow{3}{*}{ BOD } & $\mathrm{Cx}$ & $14.65+0.00$ & $11.53+\_2.23$ & $12.55+1.01$ & $11.49+1.47$ & $8.32+\_1.02$ \\
\hline & An \& Cx & $22.96+\_0.00$ & $14.69+-3.23$ & $11.29+-1.75$ & $13.58+-1.03$ & $10.42+-0.00$ \\
\hline & An & $147.7+-0.00$ & $131.05+-14.75$ & $141.12+-10.42$ & $175.69+-25.75$ & $147.04+-0.00$ \\
\hline \multirow{2}{*}{ COD } & $\mathrm{Cx}$ & $275.64+\_0.00$ & $135.87+\_60.83$ & $170.99+17.63$ & $125.36+17.29$ & 149.97+_14.71 \\
\hline & $A n \& C x$ & $232.34+-0.00$ & $209.44+-31.06$ & $154.68+-47.88$ & $214.59+-35.75$ & $161.75+-0.00$ \\
\hline
\end{tabular}

Note: An for Anopheles, Cx- Culex, DO- dissolved oxygen, BOD- Biological Oxygen Demand and COD- Chemical Oxygen Demand.
(Table 2). Culex sp was found to inhabit the gutters more than any other habitat. Out of the 27 sites where Culex sp occurred, gutter was $55.56 \%$ of the total habitat sampled for Culex sp (Table 2) and the least habitat where Culex sp occurred was the sunlit pool which was $3.70 \%$ of the total number of site sampled for Culex sp (Table 2).

Table 2: Percentage distribution of mosquito species and the breeding sites examined.

\begin{tabular}{|c|c|c|c|c|c|c|c|c|}
\hline \multirow{2}{*}{$\begin{array}{c}\text { Habitat } \\
\text { sampled }\end{array}$} & \multicolumn{2}{|c|}{ Culex sp } & \multicolumn{2}{|c|}{ Anopheles } & \multicolumn{2}{|c|}{ Both } & \multicolumn{2}{c|}{ Total } \\
\cline { 2 - 10 } & No & $\%$ & No & $\%$ & No & $\%$ & No & $\%$ \\
\hline Sunlit pool & 1 & 3.7 & 5 & 20 & 4 & 28.57 & 10 & 15.15 \\
\hline Road puddle & 4 & 14.81 & 14 & 56 & 4 & 28.57 & 22 & 33.33 \\
\hline Gutter & 15 & 55.56 & 4 & 16 & 4 & 28.57 & 23 & 34.85 \\
\hline Small drain & 5 & 18.52 & 1 & 4 & 1 & 7.14 & 7 & 10.61 \\
\hline Swamp & 2 & 7.41 & 1 & 4 & 1 & 7.14 & 4 & 6.06 \\
\hline Total & 27 & 100 & 25 & 100 & 14 & 100 & 66 & 100 \\
\hline
\end{tabular}

The road puddle had the highest record for the presence of Anopheles, out of the 25 habitats where Anopheles was found, 14 were the road puddle breeding sites of $56 \%$ of the number sampled (Table 2) and was least encountered in both small drain and swamp (7.14\%).regression model for the spatial distribution of Anopheles sp. across the studied sites was statistically insignificant at $\mathrm{P}<$ 0.05. That of Culex sp also recorded statistical insignificance for the regression model and the coefficient across the studied sites. Similar insignificance was as well recorded across the studied sites for both Anopheles sp. and Culex sp. 
The results for the physicochemical parameters with their mean values is presented in table 3 The highest temperature value of 35 oc was observed in the breeding sites of Culex sp while the least value of $250 \mathrm{c}$ was recorded for Anopheles. There was no significant difference between the BODs of the breeding sites for both genera but the BOD and DO were correlated at 0.001 level of significance. The result from the analysis done showed that there was no significance difference between the COD of the breeding sites, but the COD and conductivity are significant at $95 \%$ correlation.

\section{Discussion}

The result presented in this study showed that various habitats sampled support mosquito breeding. The presence of Culex sp. and Anopheles sp. in all the habitats sampled may be an indication of their ability to occupy a wide variety of breeding sites, which can be attributed to the availability of nutrients and food, since both species have similar feeding requirements, their occurrence together may be linked to competition for food. Chase and Knight [13] and Nikookar et al [10] had earlier reported the presence of mosquitoes in variety of breeding sites thus, this result reinforced the findings of their studies.

The result also shows that, of all the breeding sites sampled, the Gutter habitat had the highest percentage of occurrence for Culex sp. (55.56\%), while Road puddle breeding site rated highest (56\%) for Anopheles sp. Despite the differences recorded in the occurrence of mosquito species across the sampled sites, it was however statistically insignificant for the sites where either species occurred as well as the sites where both occurred. This further explains the fact that, the spatial distribution of the mosquito species across the sampled sites is not habitat dependent but closely associated with the prevailing physicochemical parameters that did not record significant statistical difference in their mean values as considered across the sites comparatively. This negates the findings of Chase and Knight [13], who reported habitat generalism by mosquito species.

Anopheles sp. on the other hand, had the highest occurrence in road puddle habitat, characterized by lack of vegetation or submerge plant as well as being open without any form of shade. It can thus be deduced that Anopheles sp. are sun loving mosquitoes. There is therefore every indication that light is a potent factor in the lives and activities of the mosquito as well as the possible nature of reduced to absence of predators within the site. The presence of Anopheles sp. in open pools in this study was contrary to the findings of Gigmig et al.[6] and Mwangangi et al. [5], that Anopheles sp. are never found in areas of open water but Foley et al [14], reported that the shaded sites supported early larval instars while late larval stage was favored by the sunnier sites.

The temperature recorded for the breeding sites may imply that the two genera of Culex and Anopheles can thrive well in open waters with this temperature range. Though, statistical difference was not recorded for the temperature values across the sites, it however depicts that the mosquito genera prevailed within the temperature range of $29-30^{\circ} \mathrm{C}$ for the breeding sites which accounted for the highest percentage value of the temperature recorded from the study. This however corroborates with the findings of Kudom et al. [15] of 29-33 and Nikookar (2017) of $20-25^{\circ} \mathrm{C}$. But contradicts the findings of Akram and Lee [16] of $19-27^{\circ} \mathrm{C}$. The temperature recorded in this study could as well be influenced by other factors such as climatic variation and geographical location of study sites.

The $\mathrm{pH}$ range recorded showed that the two genera can thrive well in an environment with a wide range of $\mathrm{pH}$. However, the narrow range of 7.7-8.9 recorded for the breeding where both co-exist may be an indication that habitat with characteristics that were strongly associated with either genus were likely to be selected by both but contradicted the report of Akram and Lee [16] of 6.97 and 7.5 of Kudom [ 1 for co-existence of mosquito genera.

The conductivity of the breeding sites shows that Culex sp can tolerate higher concentration in a given habitat than Anopheles sp. The conductivity that correlated with the distribution of Anopheles and Culex among the various types of breeding sites showed that the Anopheles tend to be excluded from sites with high conductivity values, which did not affect site selection for oviposition by Culex sp. This has a serious implication in the control of Anopheles mosquitoes. It is a known fact that it is only the Anopheles melas and Anopheles merus that can breed in saline pools. Thus, manipulating this single parameter; conductivity, that seems to determine oviposition site selection may offer a control measure against fresh water breeding Anopheles species.

The dissolved oxygen values for the breeding sites for Culex sp and Anopheles sp. sampled, implies that mosquito can adapt to oxygen differentiation within habitats. This can be implicated on the rate of biological process, because the sites with high organic matter and nutrient had a low dissolved oxygen value which may be as result of increased microbial activity occurring during the degradation of the organic matter but it had a strong negative significant correlation with biochemical oxygen demand and weak negative correlation with chemical oxygen demand.

The highest occurrence of Culex sp in the Gutter habitat which is organically polluted with high BOD and COD, showed some affinities of the genera to this particular habitat and could be implicated on the high level of organic matter that provides nutrients for the bacteria and algae used as food by mosquito larvae. This was similarly reported by Collins and Resh [17] and Dehghan et al. [18].

The biochemical oxygen demand values recorded were in line with the report of Rydzanicz and Lone [19]. However, the highest value recorded for the breeding site where both genera co-exist is an indication that both have species that can tolerate habitats with high organic load. The result is in conjunction with the findings of McCrane [20] and Kudom et al. [15] who reported that Culex sp and Anopheles sp. can respectively survive in polluted waters with organic content. This was also buttressed by the significant correlation with dissolved oxygen and chemical oxygen demand, but the impact of this phenomenon on the survival rate of the mosquito cannot be determined by this present work. 
The chemical oxygen demand (COD) shows that mosquito species can adapt in breeding sites with varying degree of organic content. Though, it does not differentiate between the oxidizing organic and the oxidizable inorganic matter in the water which makes it impossible within the scope of this study to provide the specific organic and inorganic matter that determines the breeding site of Culex and Anopheles mosquitoes. It is however possible that the COD range as recorded is the survival limit for the genera of mosquito studied.

In contrast to previous report $[18,21]$ that Anopheles sp. breeds only in clear water. It was interestingly discovered in this study that Anopheles sp. can survive in highly polluted water with high content of organic matter.

\section{Conclusion}

In conclusion, the obtained results may be of help in designing and implementing control program based on environmental manipulation.

\section{Acknowledgment}

None.

\section{Conflict of Interest}

No conflict of interests.

\section{References}

1. Azari-Hamidian S (2011) Larval habitat characteristics of the genus Anopheles (Diptera: culicidae) and a checklist of mosquitoes in Guilan province, northern Iran. Iranian Journal of Arthropod-Borne Diseases 5(1): 37-53.

2. Kenawy M, Ammar S, Abdel-Rahman H (2013) Physico-chemical characteristics of the mosquito breeding water in two urban areas of Cairo Governorate.Egypt. J Entomol Acarol Res 45: 17.

3. Harbach RH (2016) Mosquito Taxonomic Inventory.

4. WHO (2012) Cumulative number of confirmed human cases of avian influenza $\mathrm{A}(\mathrm{H} 5 \mathrm{~N} 1)$ reported to $\mathrm{WHO}$.

5. Mwangangi JM, Shililu J, Muturi EJ, Muriu S, Jacob B, et al. (2010) Anopheles larval abundance and diversity in three rice agro-village complexes Mwea irrigation scheme, central. Kenya Malaria J 9: 228.

6. Gimnig JE, Ombok M, Kamau L , Hawlley WA (2001) Characteristics of Larval Anopheline (Diptera: Culicidae) Habitats in Western Kenya. Med, Entomol 38(2): 282-288

7. Anderson RR, Harrington LC (2005) Mosquito Biology for the Homeowner. Med. Entomology Extension.

8. Nkookar SH, Fazeli-Dinan M, Azari Hamidian S, Mousavinasab SN (2017) Species composition and abundance of mosquito larvae in relation with their habitat characteristics in Mazandaran Province, northern Iran. Bulletin of Entomological Research 107(5): 598-610.

9. Orr BK, Resh VH (1992) Influence of Myriophyllum aquaticum cover on Anopheles Mosquito Abundance, Oviposition and Larval Microhabitat. Oecologia 90(4): 474-482.

10. Nkookar SH, Fazeli-Dinan M, Azari Hamidian S, Mousavinasab SN (2017) Species composition and abundance of mosquito larvae in relation with their habitat characteristics in Mazandaran Province, northern Iran. Bulletin of Entomological Research 107(5): 598-610.

11. Afolayan AA (1994) Population - Ibadan Region. Rex Charles Publication, Ibadan.

12. Areola (1994) The Spatial Growth of Ibadan city and its impact on the Rural Hinterland: Ibadan Region. Rex Charles Publication Ibadan.

13. Chase JM, Knight TM (2003) Drought-induced mosquito outbreaks in wetlands .Ecology Letters 6(11): 1017-1024.

14. Foley DH, Torres EP, Mueller I (2002) Stream bank shade and larval distribution of The Philippine malaria vector, Anopheles flavirostsis. Medical \& Vet Ento 16(4): 347-355.

15. Kudom AA, Mensah BA, Agyemang TK (2011) Characterization of Mosquito Larval and Assessment of Insecticide-resistance Status of Anopheles gambiae senso lato in Urban Areas in Southwestern Ghana. Journal of vector Ecology 37(1): 77-82

16. Akram W, Lee J (2004) Effect of habitat characteristics on the distribution and behaviour of Aedes albopictus J. of vector Ecology 29(2): 379-382.

17. Collins JN, VH Resh (1989) Measurement of temperature and light in artificial pools with reference to the larval habitat of Anopheles (Myzomyia) gambiae Giles and A(M) funestus Giles: California MVCA and University of California Mosquito Research Program,USA.

18. Dehghan H, Sadraei J ,Moosa-Kazemi S (2010) The morphological variations of Culex pipiens larvae (Diptera: Culicidae) in Yazd Province, central Iran. Iranian Journal of Arthropod-Borne Diseases 4(2): 42-49.

19. Rydzanicz K,Lone E (2003) Species Composition and Seasonal Dynamics of Mosquito Larvae in the Wooclaw, Poland area. J. of vector Ecology 28(2): 255-266

20. McCrae AWR (1984) Oviposition by African vector Mosquitoes II: Effects of site tone, water type and co-specific immatures on target selection by freshwater Anopheles gambiae, Giles sensulata Ann. Trop. Med. Parasitol 78(3): 307-348.

21. Okogun RA, Nwoke BE, Okere AX, Anosike JC, Esekhegbe AC (2003) Epidemiological Implications of Preferences of Breeding sites of Mosquito Species in Mid-Western Nigeria. Ann Agric Environ Med 10(2): $217-222$

22. Amani H, Yaghoobi-Ershadi MR, Kassiri H (2014) The ecology and larval habitats characteristics of anopheline mosquitoes (Diptera: Culicidae) in Aligudarz County (Luristan province, western Iran). Asian Pacific Journal of Tropical Biomedicine 4(sup-1): S233-S241.

23. Delong (1966) An Introduction to the study of insects. Revised Edn. Holt Renehard Winston. pp:471 - 474. 